\section{Falling victim to politics}

\author{
Stuart L. Pimm
}

The Expendable Future: US Politics and the Protection of Biological Diversity. By Richard Tobin. Duke University Press: 1991. Pp.325. Hbk £42.50, \$45; pbk $£ 17, \$ 18.75$

As species extinction accelerates worldwide, we look in despair at developing, tropical, countries that sacrifice biological riches for short-term economic gains, or even poorer reasons. Surely, in a country like the United States, with an affluent and well-educated population, circumstances should be different. As Richard Tobin explains at the beginning of The Expendable Future, the great majority of Americans believe that we should prevent extinctions. He quickly notices that surveys indicate that about 60 per cent of people with these views, also feel that "modifying the environment for human use seldom causes serious problems", and that our species "was created to rule the rest of nature". Thus, there is likely to be a wide gap between expectations and reality. Tobin documents that gap with clear writing and carefully constructed expectations of what should not, but inevitable do, fall victim to politics.

The first expectation, given the majority view, is that the US agency mainly responsible for protecting diversity, the Fish and Wildlife Service (FWS), should be wellplaced within the administrative structure. In fact, it is buried within a bureaucracy, surrounded by agencies largely devoted to the subjugation of nature. Whatever its location, the FWS can assert itself in several ways. The most crucial stage in the protection of endangered species is the first - the listing of species on the brink of extinction. This listing process began in the early 1970 s with high expectations. In 1975, with the help of the Smithsonian Institution, over 3,000 species of plants were suggested as possible candidates. The Endangered Species Act, however, contained a short, apparently innocuous paragraph that required all federallyfunded projects to not jeopardize endangered species. FWS listed the snail darter, (a small fish), challenged the Tennessee Valley Authority's construction ' of the already highly controversial Tellico Dam, and won in the US Supreme Court. The local senator, Howard Baker, had to introduce special legislation to permit the dam to be finished. Listing species became a difficult and very slow process.

The FWS maintains that its decisions to list species are based on "the best scientific and commercial data available" - just as the law requires. Listing should be on the basis of threat, not on political expediency, or whether the animal or plant is small and slimy or cuddly and large. Globally endangered species (particularly if in a monotypic genus), should receive priority over locally endangered populations of an otherwise flourishing species. Listing should be more frequent in Hawaii where most of the endangered species are to be found, than in the continental United States. In practice, the species listed tend to be local populations of large birds or mammals, in mainland areas where they cause few impediments.

In addition to listing, the FWS can designate critical habitats for species. Again expectations were high, and again, the resulting controversy often considerable, and the subsequent actions few. Rather more tangible is should we ecologists get from this book? First, the book infuses a sense of political reality: the federal government will not save small ugly invertebrates with funny sounding names; we should seek help for these species elsewhere. Second, in the decisions to save species and the habitats that house them, ecologists could do much more to become informed about where endangered species are to be found. Spending over $\$ 20$ million to save the Mississippi sandhill crane (a subspecies) and more on bald eagles than on any other single species, while very much less to save the very large number of critically endangered species of plants in the tropical forests of US states and territories (Hawaii,

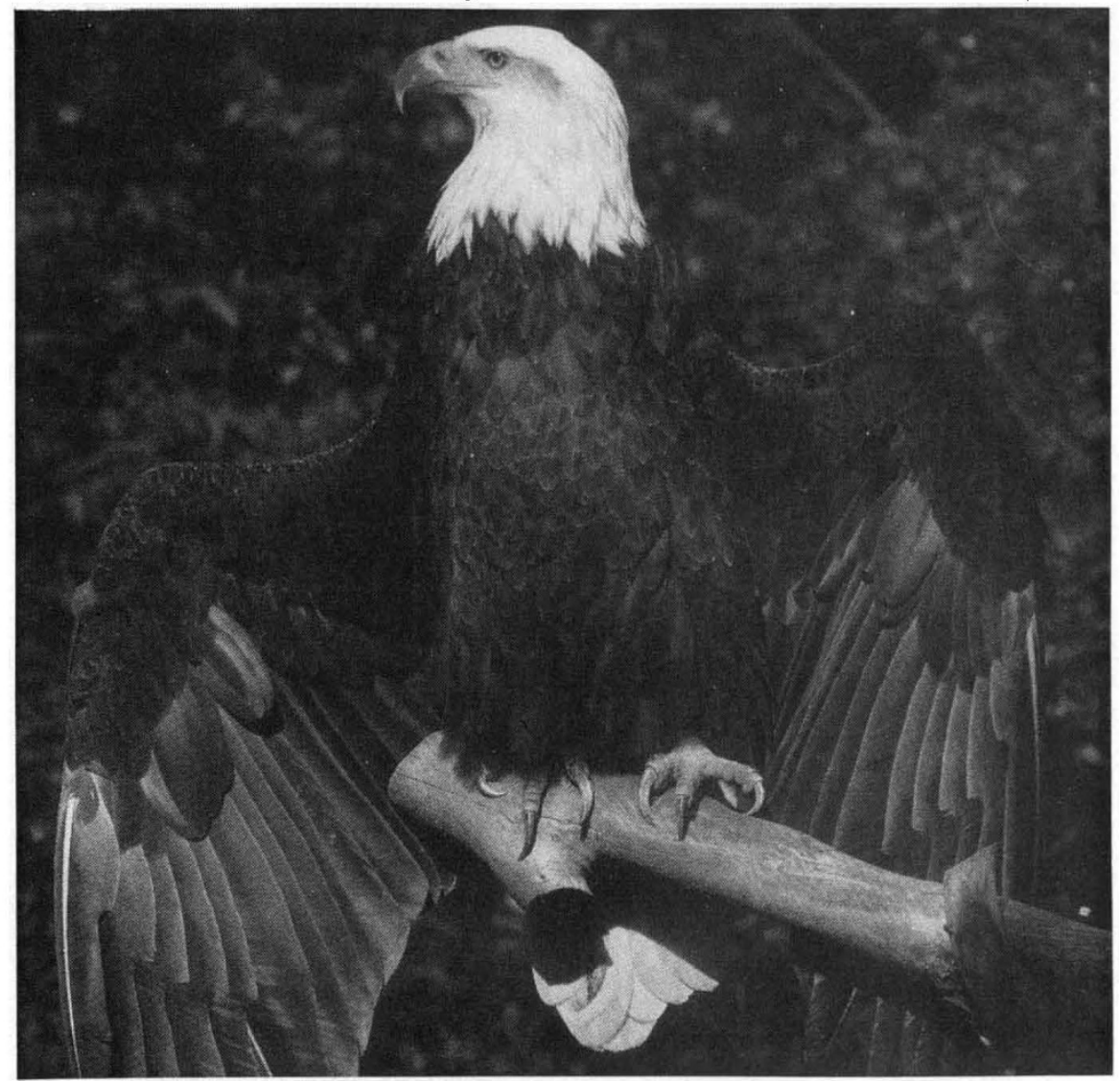

Symbol of America - the bald eagle is in no immediate danger yet receives more financial assistance than any other species. Picture from Hawks, Eagles andFalcons of North Americaby Paul A. Johnsgard (Smithsonian Institution Press, \$45, £29.95).

the acquisition of land to house endangered species. Tobin states that "considerable amounts of money have been devoted to lease purchase habitats for subspecies facing a low or medium threat and having doubtful prospects for recovery." Bald eagles have done very well financially, despite a FWS assessment that the species is in no immediate danger. Finally, there are the recovery plans - the actions proscribed to return species to better times. Again, successes are few.

The author is a political scientist and presents the organizational history, political decisions, and changing laws and administrative structures in ways that as an ecologist I found compelling and interesting. He concludes with recommendations for the politicians, lawyers and administrators. But what
Guam and other Pacific areas, Puerto Rico and other Caribbean areas) is inexcusably provincial. How can we save tropical forests worldwide if we cannot save them at home? Ecologists need to know where the diversity is, where it is threatened, and be more assertive in their priorities. Finally, there is considerable scientific uncertainty about how to determine the relative threats to species and the likelihood of recovery. Without better ecology, endangered species are going to remain potential victims of political whims.

Stuart L. Pimm is at the Department of Zoology and Graduate Program in Ecology, The University of Tennessee, Knoxville, Tennessee, 37996, USA. 